\title{
Los Catálogos de Planeamiento, una herramienta básica en la protección del patrimonio
}

\author{
$M^{a}$ Jesús Rodríguez-Tourón \\ Escudero \\ Directora del Plan Especial del \\ Conjunto Histórico de El Puerto \\ de Santa María
}

La defensa del patrimonio inmueble se atribuye en la legislación española a tres campos de competencias:

- Agricultura (parajes naturales)

- Cultura (monumentos, entornos y yacimientos arqueológicos)

- Política territorial y urbanismo (patrimonio arquitectónico y urbanístico)

El planeamiento urbanístico de ámbito municipal y el planeamiento especial incluyen en su contenido determinaciones relativas a la protección de los bienes inmuebles, y en la práctica se constituyen en los verdaderos artífices del mantenimiento del patrimonio edificado.

Desde este punto de vista, los catálogos de planeamiento cobran especial relevancia por ser habitualmente el punto de referencia en la redacción de las ordenanzas de protección, elemento clave en la evolución y transformación de la ciudad.

La reciente tendencia descentralizadora de la Administración, y la cada vez mayor atribución de competencias a los Ayuntamientos, hacen de éstos, como por otra parte ya venía ocurriendo tradicionalmente, piezas decisivas de la protección-destrucción, poniendo actualmente en sus manos competencias legales de gran transcendencia, sin una tutela objetiva para la gran masa del patrimonio edificado, sino exclusivamente para los B.I.C. o bienes con inscripción específica en el Catálogo del Patrimonio.

La asunción con plenas garantías de la responsabilidad de protección, por los Ayuntamientos, requiere la elaboración de documentos de fácil consulta e interpretación en el ámbito municipal que pormenoricen de la forma más exhaustiva posible las posibilidades de actuación en cada supuesto. La falta de precisión en la legislación vigente de las determinaciones que deben de contener estos documentos, hace que exista un variado repertorio de tipos de catálogo que con mayor o menor fortuna intentan individualizar la protección de los distintos elementos que los integran. En este sentido, se advierte que la complejidad de los catálogos es cada vez mayor, en parte debido a los avances que desde el punto de vista teórico se vienen produciendo, en parte por las carencias observadas en la puesta en práctica de los mismos, y por último por la citada cada vez mayor autonomía de los Ayuntamientos.

Nuestra propia experiencia en la elaboración de trabajos relacionados con la catalogación, nos ha llevado a matizar los contenidos de las fichas de catálogo poniendo mayor énfasis actualmente en las condiciones de ordenación, y ello por estar en el convencimiento de que la mayor parte de las veces son cuestiones de índole económica (volúmen-aprovechamiento, ordenación-ordenanza) tan ajenas a la sensibilidad histórico-artística, las que deciden sobre tal o cual bien.

La metodología, procedimiento y en definitiva protección de las actuaciones sobre los BIC está suficientemente desarrollada y contrastada, no siendo además competencia de la Administración Local, y por tanto no es objetivo principal de los Catálogos de Planeamiento, que se limitan a considerar estos bienes como integrantes de su contenido, con el máximo nivel de protección que en ellos se determine. Sin embargo, la gran masa del patrimonio edificado, cuyo interés es indudable, aún no mereciendo la categoría de BIC, es lo que conforma el mayor porcentaje de nuestros pueblos y ciudades y en ella se centran los Catálogos de Planeamiento. Es función pues del Catálogo, definir de la forma más rigurosa y pormenorizada posible las variables de todo tipo que inciden en la comprensión y evolución de esa "arquitectura menor" definidora de paisajes urbanos característicos e idiosincrasias particulares. Tan importante puede ser el Conjunto que rodea a la pieza (Entorno lejano) como la pieza en sí.

La práctica cotidiana de la valoración de las propuestas de intervención en edificios históricos menores, nos lleva a la certeza de que es preciso un documento de síntesis que pueda ser utilizado como referencia básica en la toma de decisiones. Este documento deberá contener, en la medida de lo posible, y en un gradiente asociado al nivel de protección o grado de interés del Bien, datos de distinta índole, tanto históricos como estilísticos, constructivos, jurídicos y de obligado cumplimiento.

Por tanto, y en las circunstancias actuales es preciso la redacción de un catálogo de planeamiento desde los siguientes puntos de vista.

- Información
- Protección
- Ordenación

Se requiere para ello la formación de un equipo multidisciplinar que comprenda desde Historiadores, Ar- 
queólogos, Arquitectos, Restauradores,..., etc. que bien a nivel consultivo o propositivo aporten en cada inmueble catalogado su particular punto de vista. La intervención de todos estos profesionales se hace imprescindible en los contenidos de información del Catálogo, que serán por otra parte la base históricocientífica en la que apoyar las posibles intervenciones. La metodología propuesta es la habitual en la redacción de un instrumento de planeamiento, con ligeras matizaciones por razón de la materia tratada, es decir:

Información: recogida de cuestiones a catalogar, conteniendo datos históricos; fecha de construcción, autor o autores, fechas de eventos ocurridos en el inmueble, reformas acaecidas en el transcurso del tiempo, autores, propietarios, cambios de uso, etc. que nos acercarán al edificio "conociendo su evolución".

Datos de régimen de tenencia, situación legal y de estado de la edificación o bien catalogado, pormenorizado a sus componentes con vistas a una posible valoración económica de su rehabilitación. Esta fase informativa estará naturalmente abierta a posibles incorporaciones que a raiz de los diversos estudios que puedan realizarse, se lleven a cabo, pudiendo enriquecerse con aportaciones de distintos campos en el transcurso del tiempo, motivando incluso a la vista de las mismas, diferentes modificaciones en los niveles de protección asignados.

Es conveniente que esta parcela informativa del catálogo incluya la representación gráfica del edificio o Bien en el momento de su redacción, así como cuantas referencias bibliográficas $y / o$ archivisticas se hayan localizado de planimetrias anteriores.

El análisis de las variables obtenidas cristalizará en la aplicación de un nivel de protección, que será a la postre, del que se deriven las posibilidades de intervención. Tradicionalmente se han venido manejando de tres a cinco niveles de protección que se han aplicado a los bienes. En nuestra opinión, es preferible simplificar los grados, con el fin de centrar las cuestiones de forma inequivoca y no hacer farragosa la parte propositiva (Ordenanza concordante). Sin embargo esta reducción de los grados de protección deberá llevar implicito un mayor estudio individualizado del catálogo, a fin de hacer posible proteger lo realmente protegible y posibilitar la renovación de partes sin interés.

En este sentido, y en un intento de sistematizar la toma de datos de campo nuestro trabajo en el Catálogo de El Puerto de Santa María, se ha realizado partiendo de la localización en primer lugar de los invariantes arquitectónicos de la arquitectura local, en número de 39 y aplicados a cada edificio nos va a dar una primera aproximación individualizada del mismo. Este método de toma de datos exhaustiva de invariantes en cada edificio, sí bien es laborioso, permite su fácil informatización y por tanto baremación, lo cual desemboca en una pre-asignación de niveles de protección, que sí bien preveíamos burda, finalmente se ha comprobado que se ajusta bastante acertadamente a la valoración realizada manejando otros elementos del análisis. Por otra parte, también se ha revelado interesante a la hora de interpretar la reimplantación tipológica, centrando la discusión en los invariantes definidores o característicos en cada caso, en un intento de fluidificar el debate interpretativo que siempre se suscita en la práctica profesional sobre estas cuestiones.

Los tipos de protección se extienden habitualmente, a edificaciones, elementos individualizados, zonas urbanas (jardínes y parques), visualizaciones y yacimientos arqueológicos. La protección de cada uno de estos tipos, se estructura en tres grados jerarquizados que suelen atender a la terminología siguiente: Integral, Estructural y Ambiental.

La protección Integral se aplica a aquellos bienes que al poseer valores arquitectónicos, históricos, patrimoniales, excepcionales, deberán ser conservados integramente, preservándose por tanto todas sus características, y significación cultural en la escena urbana. Son bienes equiparables a los B.I.C. que determina la L.P.H.E.

La protección estructural se asigna a bienes que por sus características tipológicas estilísticas, o valor histórico, se singularizan en la masa edificada, debiendo preservarse los elementos estructurales configuradores del inmueble. En general, este grado se aplica a edificios con valores tipológicos característicos.

El nivel de Protección Ambiental, se asigna a edificios o espacios urbanos, que sin detentar especiales características de calidad arquitectónica o significación histórica individual, conforman áreas de interés, colaborando a la calidad de la escena urbana.

Estos tres niveles o grados de protección constituyen la base clasificatoria de los bienes catalogables, pudiendo homogeneizar según estas categorías los distintos supuestos, articulando posteriormente una ordenanza genérica que regule las actuaciones en los mismos.

Pero, como ya hemos dicho antes, las determinaciones de protección, deben ser en los catálogos actuales muy precisas, a fin de constituir una guía clara de lo que es posible realizar. Por tanto, encontramos fundamental, expresar en las determinaciones de protección pormenorizadas a parcela como son:

\section{Elementos a conservar:}

Donde figurará una identificación precisa de aquellos elementos que independiente del nivel de protección asignado deban ser conservados integramente. Se deberá prestar aquí particular atención a elementos que, por no formar parte definidora de la construcción, sean facilmente destruibles o intercambiables (barandillas, puertas, alacenas, capillas, escudos,...) en detrimento, de las tipologías locales.

\section{Acciones impuestas:}

Se trata de pormenorizar para cada edificio o elemento aquellas actuaciones que obligatoriamente deberán ejecutarse, teniendo la misma consideración a efectos normativos que un "fuera de ordenanza".

Estas actuaciones se centran principalmente en la eliminación de todo tipo de añadidos y huecos que distorsionan la lectura del inmueble, (marquesinas y escaparates en locales comerciales, ocupación de patios,..., etc.). 


\section{Recomendaciones:}

Este aspecto irá encaminado a la orientación en lo relativo a protección del patrimonio, en aquellos casos en los que por la escasa entidad de las actuaciones a realizar, no se precisa de un arquitecto en la redacción del proyecto. Deberán consignarse, desde materiales a emplear, hasta posibilidades de color si éste adquiere especial relevancia de entorno, $y$ en general todo tipo de acabados.

Por último el Catálogo como documento completo que proponemos, deberá expresar sintéticamente las condiciones de ordenación que en el Planeamiento urbanístico que le afecte le sean de aplicación, a fin de resultar imprescindible su consulta para obtener una información total sobre el inmueble, impidiendo la dispersión de datos y la busqueda tantas veces infructuosa de relaciones ordenanza-protección.

En el sentido anteriormente expresado las condiciones de ordenación deberán contemplar en síntesis: estudiosos un punto de partida para la investigación y/o toma de decisiones sobre las actuaciones posibles en el inmueble.

Por otra parte se sintetizan las posibilidades de actuación en una rápida impresión visual, y en la misma ficha en que tienen cabida los datos históricos, motivo por el cual es dificial obviarlos.

La dificultad de cohesionar datos provinientes de fuentes diversas, hace según nos demuestra la experiencia, que la mayor parte de las veces se realicen acciones deficientes sobre los Bienes catalogados, por falta de mayor conocimiento sobre los mismos. En este sentido, el Catálogo debe de servir también como incentivador de la puesta en valor de las referencias histórico-patrimoniales del inmueble.

Al considerar los catálogos de Planeamiento como instrumentos abiertos, que deberán ponerse al día continuamente, se hace imprescindible su informatización, y

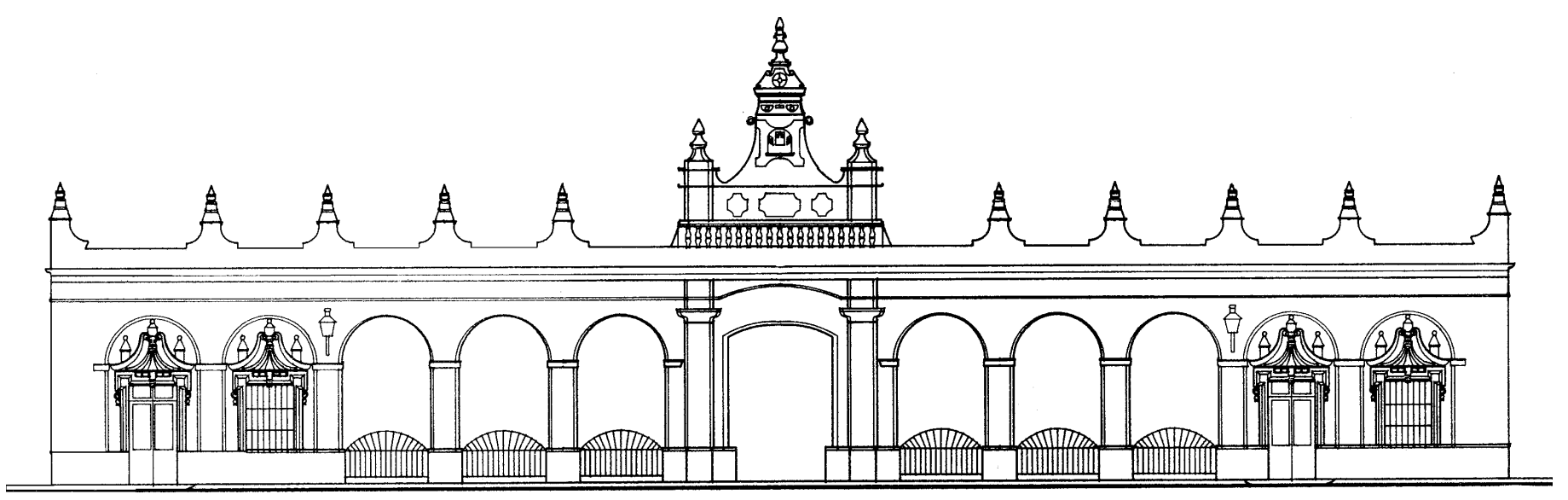

Alzado principal antigua lonja de pescado Escala 1: 200

- Régimen de suelo. Atendiendo a su clasificación.

- Ordenanza de aplicación; con referencia al articulado del Plan o Norma vigente, y expresión pormenorizada del mismo sobre parcelación, usos admisibles o expresamente prohibidos, edificación, ordenanza estética, tipos de obras permitidas o expresamente prohibidas, alturas asignadas y condiciones de entorno.

- Actuaciones previstas sobre el bien en el Planeamiento con expresión de sus plazos.

- Datos correspondientes al Área de Reparto y Aprovechamiento tipo.

Con todos los datos anteriores y la documentación gráfica que haya sido posible realizar, plantas, alzados y/o fotografías, se obtiene una lectura sintética y completa del Bien, que se plantea como elemento básico en la toma de decisiones sobre el mismo.

Estimamos desde este planteamiento integrador del Catálogo, que su función dentro del Urbanismo actual es doble. creación de una base de datos, que previa digitalización cartográfica, pueda relacionar elementos gráficos y alfanuméricos, pudiendo entonces cruzarse todo tipo de variables y permitiendo la obtención de conclusiones temáticas y la fácil consulta de la Documentación existente. Para ello parecen revelarse en la actualidad como herramientas muy útiles, los Sistemas de Información Geográfica que asociados a programas avanzados de dibujo (Microestation o similar) generan resultados satisfactorios.

Es interesante, que el diseño de la ficha sea tal, que permita incluir en la misma página las determinaciones de protección y ordenación, a fin tanto de consultarlas simultáneamente, como de permitir su puesta al día a medida que varien las condiciones de planeamiento, 0 se hayan realizado actuaciones en el Bien.

En conclusión, deberemos adaptar los Catálogos de Planeamiento a la realidad de la sociedad actual convirtiéndolos en una herramienta práctica que sea imprescindible utilizar en el día a día de la formación de la ciudad, y no sólo en un ejercicio de mera erudición que a tan pocos alcanza. 